\title{
Encontrar a Vida, transformar o Mundo Pensar uma existência ético-estética segundo o Corpo e o Encontro
}

\author{
Fernando Machado Silva
}

Um corpo é um complexo de forças regido

maioritariamente, pelas duas forças da Vida: a mimésis e a poiésis; ele próprio é uma expressão da vida, a efectuação e contra-efectuação de um Acontecimento. As experiências são impessoais, neutras, a-significantes, e o propósito das técnicas e práticas das artes do corpo serve menos a construção de uma subjectividade, de um eu, do que a desconstrução dessa mesma subjectividade; menos a construção de um corpo como meio capaz e eficaz para fins artísticos, do que a procura das suas potências para libertar a vida onde ela está presa, como diz Deleuze sobre a arte. Assim, a "ascese" é um incessante exercicio de práticas e técnicas procurando evitar qualquer estratificação de uma subjectividade e de uma significância. Pelo que a análise das práticas e técnicas do corpo, pautando-se por questões biológicas, fisiológicas, sociais, políticas e filosóficas, deverá incidir no modo como se faz a passagem, para usar os conceitos de Eugenio Barba, de um corpoquotidiano para um corpo-extra-quotidiano, um corpo a caminho da sua máxima potência e ao encontro da Vida impessoal e imanente. Este será um meio, entre vários, de se "encontrar a Vida". Como faremos, então, para "transformar o mundo"? A nossa proposta passa pelo conceito de "encontro".

0 "encontro" é o grau zero da ética-estética, é o "encontro de ritmos". Se se quiser separar a ética da estética, isso far-se-á pela inclusão de um corpo: dois corpos para a ética (sendo este encontro já estético, no sentido etimológico, de sensações) e um terceiro, como testemunha, afectando o encontro desses dois corpos (entendendo a estética aqui no seu sentido mais geral). Porém, entre esta libertação da Vida e a transformação do mundo cada um terá de incitar em si um "salto da vontade" e, nesse salto, levar o corpo à sua máxima potência e, tornado plena "hecceidade", que a cada relação se conecte de modo a levar o outro corpo ao limite e, de queda em queda, de sensação em sensação, deformar de tal forma o corpo que já nada o difira da Vida, construindo assim a Anarquia no seu sentido mais rigoroso, um êthos horizontal em que cada relação de forças afecta e é afectada de igual intensidade. A dificuldade, a radicalidade e o perigo desta aventura residem precisamente na transformação do mais concreto das máquinas abstractas, os corpos e suas relações, a forma molecular das moles; e se o corpo - no sentido em que o entendemos, ou seja, "uma vida" - não se transformar, nenhuma transformação se dará.

Esta noção de "encontro" é pautada pelo conceito de devir deleuzeano, de acordo com "uma zona de vizinhança ou de co-presença" (Deleuze / Guattari, 1980: 334, itálico dos autores). Se, segundo o filósofo, uma "hecceidade" é inseparável de uma névoa dependente de uma zona molecular com a qual estabelece uma relação de vizinhança induzindo e determinando o seu movimento e repouso; e sendo já nós uma "hecceidade" ou conjunto de "hecceidades, o encontro", ou o devir, só pode descobrir o fundo da relação se o corpo-sujeito se "despir" dos seus estratos ${ }^{1}$.para assim, nu de subjectividade e significância, permitir a mistura nessa zona indiscernivel e indeterminada proporcionada pela vizinhança, fazendo ressaltar o comum dos dois corpos e vivido pelos corpos, razão pela qual o devir não é nem identificação, nem imitação, mas criação.

0 telos da "ascese" da prática artística, na nossa proposta, procura o pôr-se a nu, o despojamento do excessivo, dependendo principalmente de uma transformação da percepção. É certo que há uma profundidade bem real da matéria que compõe um corpo, cuja organização determina o organismo com suas estratificações e contra o qual o CsO se opõe com os seus devires. Não negamos essa premissa. Contestamos antes a profundidade escura e abismal da tópica freudiana preferindo, por a vivermos, a noção de estado de atenção, expandido ou concentrado bem superficial. Nós estamos imersos em relações de forças, as quais, todas elas, à excepção das que se mostram através das perceções macroscópicas, se movem ao nível micro-atómico, na dimensão das pequenas-percepções. A expressão virtual da Vida é totalmente incorporal, mas o único meio de a sua expressão se tornar actual é pelo meio de uma corporização. 0 corporal e o incorporal ocupam o mesmo espaço segundo duas dimensões diferentes em permanente contacto, um mais próximo das pequenas-percepções, o outro das macro-percepções. A separação das duas dimensões depende principalmente do plano, de uma maior ou menor estratificação promovida pela afirmação do transcendental; e o propósito que procuramos com o
'Talvez o "horror" da nudez se encontr propriamente aqui, não na nudez de uma corporeidade mas no despir de todos os dispositivos e um corpo apresentar-se como vida, dai não ser estranho que Agamben, no fim do seu artigo intitulado,

justamente, "Nudez", nos diga: "[o] matema da nudez é, neste sentido, simplesmente: haecce!, 'não há nada a não ser isto'" (Agamben 2010: 104, itálico do autor

Fernando Machado Silva é actor, performer, assistente de encenação, doutorando em Filosofia Contemporânea pela FLUL e membro do CFCUL e da associação internacional Performance Philosophy. 
evidenciar de uma ascese da prática artística do corpo, por ser ele o mais "castigado" e o local pelo qual se acede ao incorporal obstruindo a expressão da Vida, de "uma vida", é o de uma busca da plena justeza das duas dimensões, a sua não-separação. Só com uma prática que elimina quer a ideia de uma separação, quer a prática de tal separação e, desta posição, ir corroendo todas as relações, todos os dispositivos que fundam as várias estratificações, se pode, enfim, libertar a Vida. A transformação dá-se pelo "encontro", pelo encontro de ritmos, pelos agenciamentos. Se já antes tínhamos dito que o "encontro", era o de dois corpos, de ritmos, o que pressupõe que um corpo é, em si, um ritmo, cremos que o modo como a Vida se efectua e contra-efectua num corpo se faz por ritornello.

Sobriedade, devires, afectos, ritmo, agenciamento, tudo isso compõe, ou deveria compôr uma técnica do corpo, uma "ascese" que, enquanto o forma, o deforma; uma prática que se inicia num agenciamento artístico para libertar a vida e, por fim, ir minando, partindo, fracturando, abrindo o seu caminho, pela afirmação de um êthos, até romper todas as estratificações do socius e chegar-se à ordem do Cosmos, à Vida por ela mesma, a Anarquia. Por isso um corpo é um ritornelo no sentido último proposto por Deleuze / Guattari, um "cristal de espaço-tempo" "[agindo] sobre aquilo que o rodeia, som ou luz [outros corpos, instituições, dispositivos, etc.], para tirar dai vibrações variadas, decomposições, projecções e transformações" (ibid.: 430). A questão aqui é a de perceber que os corpos são continuamente lançados em modelos arborescentes, identificatórios, representativos, embora ilusoriamente deixados a prosseguir um "bem maior", delineado por uma biopolítica que abraça a vida do corpo e a libertação de uma individualidade.

0 "encontro" de corpos, esse que consubstancia uma ética, deve procurar, igualmente, ou estar atento ao brotar desse novo ritmo, começando antes de mais com outro processo de identificação. 0 "desnudamento" do corpo que referimos, o pôr-se a nu de subjectividade e significância de modo a produzir-se uma zona de indiscernibilidade passivel de fazer ressaltar o comum entre duas vidas e soltar as linhas de um devir - um momento de criação -, parece-nos ser o traço que falta às três características distintivas do processo oferecido por Deleuze em "Bartleby", embora o desnudar possa ser entendido, também, como um dos resultados finais do "encontro", ou seja, é preciso um desnudamento forçado para se alcançar um desnudamento vital. Assim, o "encontro", de acordo com a fórmula deleuzo-bartlebyana, requer um "traço" de expressão, uma "zona" de indistinção (ou de indiscernibilidade, de ambiguidade) e uma "função" de fraternidade universal. A primeira opõe-se à apropriação

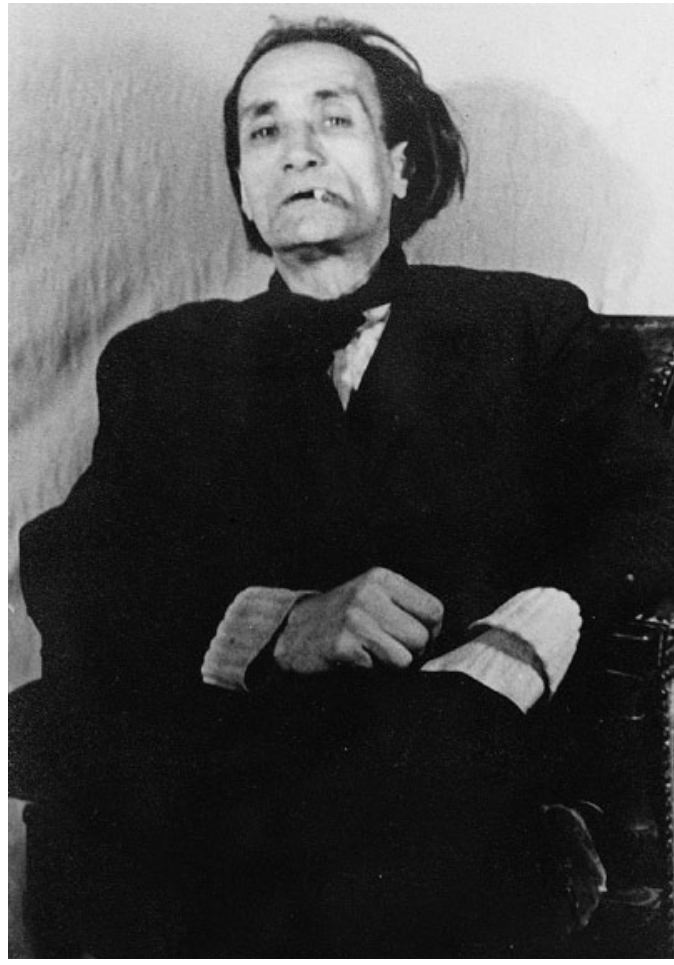

e adaptação da imagem ou da forma, para uma recolha e procura de conexão das marcas dos corpos e do agenciamento a ser produzido; a segunda trata de estabelecer um espaço de forças de onde se pode traçar um devir, no qual um sujeito afim de uma subjectividade e significância se desvanece: é o espaço de relação das pequenas-percepções, das singularidades, da queda das sensações, de choque de ritmos pessoais para um impessoal, da própria zona; a terceira impede a rivalidade mimética desencadeada pelo processo anteriormente referido. Tal como nos informa Deleuze, essa rivalidade mimética decorre da mobilização de uma função paterna "a imagem é por excelência uma imagem de pai, e o sujeito é um filho, mesmo se as determinações se alterarem" (Deleuze 1993: 99). Esta função de fraternidade faz-se sobre a ruína dessa imagem, busca a solvência da imagem pai, da lei, da moral, afim de instaurar laços de aliança fazendo com que cada um seja irmão/irmã do outro, mas também um outro nó nos laços de coração, uma amizade que já não será "uma circunstância exterior mais ou menos favorável, mas, permanecendo todavia a mais concreta, uma condição interior do pensamento como tal" (idem 2003: 307), pois é com o amigo/a concreto/a e com aquele que não há, dir-nos-ia Derrida, o amigo/a por vir, do porvir ou no devir desse povo que falta e que vem, "que se atravessam as provas como a amnésia, a afasia, necessárias a todo o pensamento" (Deleuze apud ibid.). É deste modo que o "encontro" afecta simultaneamente o corporal e o incorporal. Há - através da prática do corpo, tais como exercícios de ritmo, de resistência, de agilidade, de fluidez que ajudam a desnudar, forçam o desnudamento, o qual implica uma paulatina dilatação do "estado de atenção" e não do teatro do inconsciente - alterações de ritmos vitais, transformações que obliteram as estratificações. Pense-se no estranho kata cabalístico de Antonin Artaud em "Um atleta da afectividade": mediante três tipos diferentes de localização da respiração, conjuntamente 


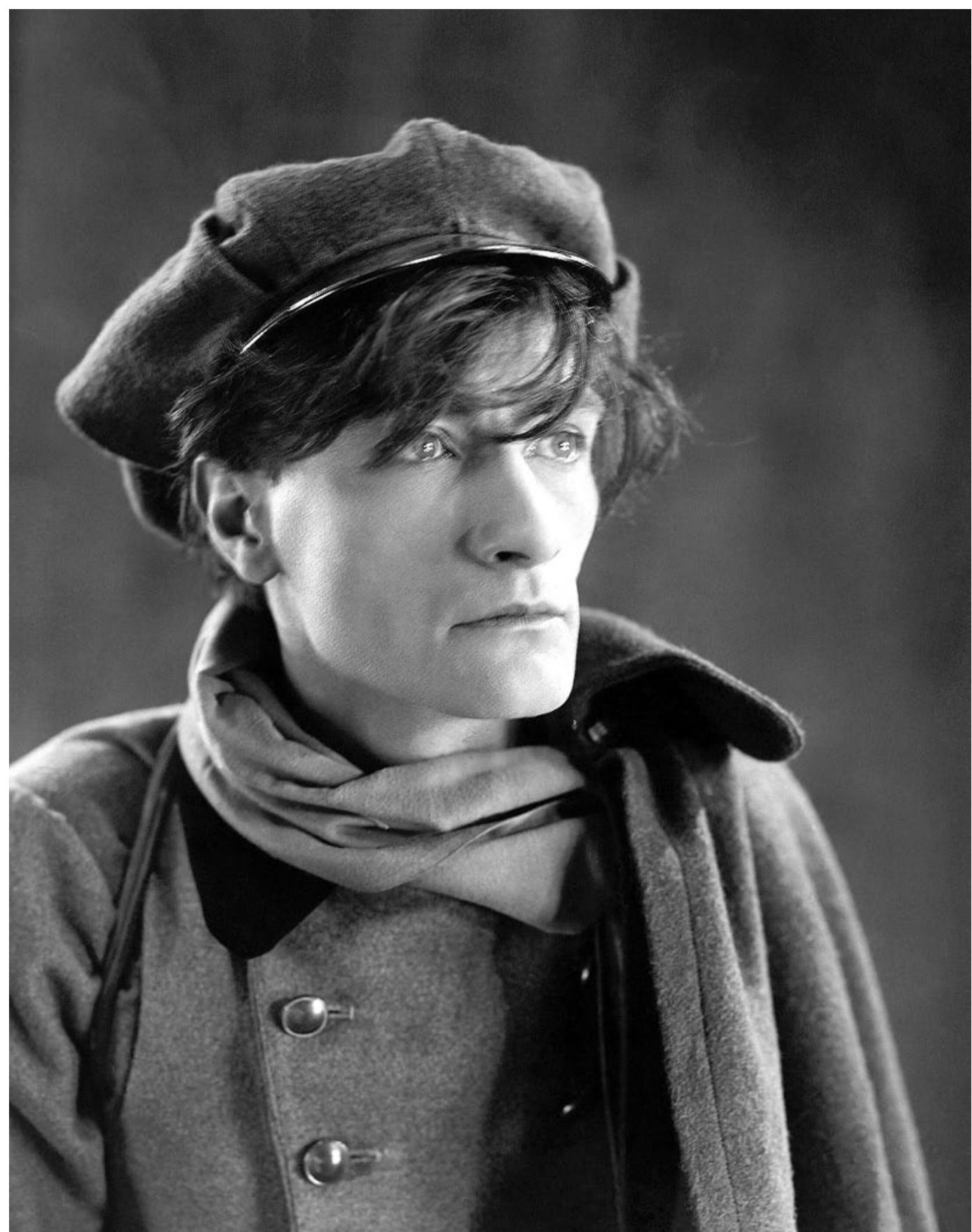

com o deslocamento de forças que alteram o equilibrio chegamos a uma experimentação dos afectos, das emoções e sensações totalmente independentes de psicologismo, significância e subjectividade. Ou então o particular exercício, dentro e fora de cena, dos actores Nô e Kabuki e recuperado pelo Butoh, denominado de jo-ha-kyu, que significa à letra princípio-quebra (ou mudança)-rapidez, amplamente analisada por Eugenio Barba em Canoa de papel. Nestes exemplos não há possível mecanização do movimento em si e a "atenção" concentra-se em absoluto no devir do próprio movimento, nas flutuações de energia, nas quedas das sensações. Todas estas experimentações de ritmos, sensações, respirações, movimentos têm o seu reflexo no incorporal, alteram os esquematismos miméticos de identificação, do próprio pensamento e do "estado de atenção".
Ora, se o "encontro" se diz como propulsor de uma ética-estética constituído por quatro condições, teremos, igualmente, de evidenciar que não se ampara em condições transcendentais aquém das condições imanentes que se geram com a produção de um plano de criação. 0

"encontro" surge, pois, tal como o plano de imanência deleuzo-guattariano. Ele é, por um lado, estritamente amoral e, por outro lado, à medida que se vai dando forma a sua consistência, encontrando os seus ritmos, deixando as suas marcas, definindo as suas zonas, descortinando o modo da sua função, a diferentes graus de intensidade. A cada "encontro" a sua ética! De um "encontro" entre dois corpos resulta uma ética, mas o reencontro desses mesmos dois corpos pode resultar no desconcerto do anterior, um ganho ou uma perda, ou mais precisamente uma queda. Todavia, haverá sempre um plano, por mais 
frágil que seja, resultante do primeiro "encontro" e transportado para o próximo. 0 que é incerto é a ética criada ser a mesma num outro com diferentes corpos, entre um que já passou por um e outro, ambos vindo a produzir um novo "encontro". Dir-se-á, por um lado, que há uma ética do encontro, dependendo das quatro condições e resultando uma ética e, por outro, há o "encontro" de éticas, no sentido de mistura de ritmos de dois modos de existência. De um modo ou de outro há criação de um novo corpo, um diferente do corpoquotidiano, e o propósito será o de contagiar todas as relações, atravessá-las, colocando em questão o problemático de cada corpo e do seu êthos. A criação de um impessoal, de uma sociedade de impessoais e sem apropriação.

Há diferenças que se podem esboçar entre o "encontro" desenvolvido numa ascética da prática do corpo e essoutro que atravessa a máquina da arte e contagia o social. $\mathrm{Na}$ máquina o "encontro" é todo o processo que tende para um "espaço do Acontecimento", máquina dentro da máquina com o propósito de arrancar a vida, espécie de ante-cena do social, experimentalismo com o intuito próprio da criação artística. Porém, tratando-se de uma "ascética" e de uma real ante-cena, o "encontro" deve ser lançado para fora de toda a cena, ou seja, produzir um corpo-extra-quotidiano que obste à clausura e à territorialização pela máquina, lutando constantemente contra a sua estratificação. Os corpos-extra-quotidianos, percorrendo as mesmas ruas, deverão contagiar, arrastar os corpos-quotidianos nos seus devires, espécie de electrões radicais que afectam uma molécula excitando-a de modo a atingir outro grau de intensidade, para desintegrá-la e saltar em direcção a outra. Esta é a grande diferença entre os dois "encontros": um é ainda mediático e mediado, o outro imediático e imediado, um outro tipo de "espaço do Acontecimento" ou, nas palavras de Hakim Bey, uma "zona autónoma temporária" (temporary autonomous zone) (Bey 1994: 17).

0 "encontro" pode ser nada mais que o encontro físico para um café ao fim da tarde, mas a dificuldade está no que ele implica: o desnudamento, a procura de uma desestratificação, um abandono de toda a moral e ética, ancoradas num transcendental, de modo a que se criem outras. É um espaço de pura vontade e desejo, mas de outra natureza. A crítica comum à Anarquia surge precisamente porque se faz dentro de um enquadramento capitalista que alimenta o sentido do desejo enquanto falta, da luta cega por uma individualidade, uma subjectividade votada a desprezar a vida e todas as suas potências, a expressão execrável do pensamento de uma sub-vida de remorsos e ressentimentos. 0 "encontro" é um espaço de vontade de vida, de força, de procura da fluidez do desejo, experimentalismo do que pode um corpo, o qual só pode acontecer se se deixar de tomar o corpo como meio de uma qualquer instância fora da imanência. 0 que há a fazer é "aqui", de mão-a-mão, de boca-a-boca, de respiração-a-respiração, face-a-face, corpo-a-corpo, tornando horizontais todo o tipo de relações, as quais nunca chegarão alguma vez a sê-lo se não se procurar, também, transfigurar os processos de identificação miméticos em poiéticos. É um trabalho duro, solitário, uma ascese infinita porque nunca se sairá da fronteira, mas igualmente uma certa "arte de si" feita em conjunto entre corpos, falhando e caindo uma e outra vez. É na prática artística do corpo - não acomodada a uma só técnica e respigada aqui e ali, construindo um agenciamento, expandindo o "estado de atenção", promovendo a abertura atenta às pequenas-percepções, aos devires, às forças, prática tornada "obscena" (saindo da cena), executada na vida quotidiana a cada passo, gesto, respiração, olhar, palavra - que conseguimos arranhar a superficie do problema do Corpo-Vida. Talvez a questão seja afinal como construir para si um ritornello, como encontrar o seu ritornello, pois este passa por um CsO: ir ao "encontro" da Vida, dançar os seus sins apapa-pa-pai-xonadamente, com um salto da vontade até que corpo e pensamento caiam com o mesmo peso.

\section{Referências bibliográficas}

AGAMBEN, Giorgio (2010), Nudez, Lisboa, Relógio d'Água Editores, col. Filosofia.

BAY, Hakim (1994), Immediatism: Essays by Hakim Bey, Edinburgh and San Francisco, AK Press, $2^{\text {nd }}$ edition, (1992).

DELEUZE, Gilles (1993), Critique et clinique, Paris, Les Éditions de Minuit, col. Critiques.

-- (2003), Pourparler, 1970-1990, Paris, Éditions de Minuit, col. Reprise, (1990).

DELEUZE, Gilles / GUATTARI, Félix (1980), Mille plateaux, Paris, Les Éditions de Minuit, col. Critique. 